[Nippon Nögeikagaku Kaishi Vol.65, No.2, pp. 171 176, 1991]

\title{
食物繊維の水中沈定体積とアマランス毒性阻止効果に 及ぼす粒度の影響十
}

\author{
武田秀敏*, 桐山修八** \\ (愛缓大学農学部農芸化学科, 現在, *今治明德短期大学生活科学科, \\ **北海道大学農学部農芸科学科)
}

(平成 2 年 9 月 28 日受理)

Effect of Particle Size of Dietary Fiber on Its Settling Volume in Water and

Protective Activity against Amaranth (Food Red No.2) Toxicity in Rats

Hidetoshi TAKEDA* and Shuhachi KIRIYAMA**

Department of Agricultural Chemistry, Faculty of Agriculture, Ehime

University, Matsuyama, Ehime 790.

(Present address) * Imabari Meitoku Junior College, Imabari, 794

** Department of Agricultural Chemistry, Faculty of

Agriculture, Hokkaido University, Sapporo, 060

\begin{abstract}
We prepared four particle sizes(PS : $<1 \mathrm{~mm}, \quad<149 \mu,<74 \mu$ and $12 \mu$ ) of dietary fiber of the root of edible burdock (Arctium lappa L.), "gobo" (GDF). Their protective activity against amaranth (Food Red No.2) toxicity was tested by their capacity to ameliorate the retarded growth rate of rats fed 4 or $5 \%$ amaranth. Holocellulose from GDF (PS: $<1 \mathrm{~mm}$ ), commercially available cellulose powder (prepared from cotton fiber, PS : 74 to $149 \mu$ ) and powdered polystyrene foam (PS : $<1 \mathrm{~mm}$ ) were also examined. The settling volumes in water ( $\mathrm{SV}, \mathrm{ml} / \mathrm{g}$ airdried matter) of these samples were determined to examine the correlation between their bulk forming capacity and protective activity. A decrease in GDF particle size caused a decrease in its SV value and protective activity. Powdered polystyrene foam $(5 \%)$ showed a beneficial effect whereas cellulose did not have a favorable effect at the same level. Holocellulose also showed a beneficial effect enen at a $1.5 \%$ level. The protective activity of dietary fibers was roughly correlated with their SV value, although an equivalent effect was not obtained consistently when relative SV values \{specific SV of each sample $(\mathrm{ml} / \mathrm{g})$ times its dietary level $(\%)$ \} were equalized between diets containing different dietary fibers by adjusting their dietary level. These results suggest that the bulk forming capacity of dietary fibers determined by SV values (in vitro SV) should be altered after enzymatic digestion, and the altered SV value in the gastrointestinal tract (in vivo SV) determines its effectiveness.

(Received September 28, 1990)
\end{abstract}$$
\text { 緒 帚 }
$$

食物瀻維は，アマランス（食用赤色 2 号）の大宣投与 によるラットの成長㧕制をほ注完全に阻止する わゆるこの毒性阻止效果は，食物繊維のアマランス吸着 作用によるものではなく，食物絨維の物性，とくに水中 沈定体皘 (Settling volume, SV; ml/g dry matter) $\measuredangle$ 密接に関係していだ(3)。すなから，ラットの精製飼料に

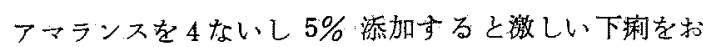

†ここでいう“毒性”や，“毒性阻止効果”は便宜的に 使っている呼称で，国際的にす通用しているもので す(11-14)。るbらん，毒性学上の基準によれば動物の

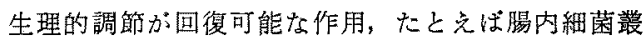
の变化や，非吸收性物質の大量投与に上る下痢作用， 体董增加密の低下などは，磁密には量性作用とはみ なさないことになって扣り(15)，毒性学の定義でい ら“毒物”に当たらないことはすでに郝りしてい る(16). したがって，ここでいう“毒性”ゃ，“掊性 阻止效果”は、正確には。アマランスの大量投与に よる成長遅延と.その改善効果ということで岕る。 
こし，成長は著しく遲れるが，この飼料にさらに $5 \%$ 前 後の食物緎維を同時添加するとアマランスの害作用は阻

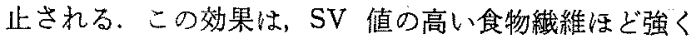
現れる(3)

そこで今回，食物織維源を機械的に破壊して粒径を小 さくすることにより，同一の出発物質から SV 值の異な る試料を調製し，それらの生理効果を比較した。 また， 異なる SV 值を有する数種の食物繊維源について，それ らの添加レベルを調節して飼料中で占める相対 SV 值を 計算上等しくした場合の生理効果の等価性についても検 討した，をの結果，同一成分からなる食物絨維でも，粒 径が小さくなると SV 值が低下すると同時に，生理効果 も有意比弱くなった。乙か乙生理効果の低下は，SV 值 の低下ほど著しくなかった、したがって，食物瀻維間の 質的な差も生理効果に関係していることが示唆された。 また今回，発泡スチロール粉末でも食物緎維之類似の効 果を発揮することもわかったので報告しておきたい，

\section{実 験 方 法}

\section{1. 食物䋐維試料とその調製食物瀻維試料は,} 従来の力法 ${ }^{(2,3)}$ 準じてゴボウから調製した（以下 Gobo Dietary Fiber, GDF と略). 市眅のセルロース粉末(綿 花から調製したもの，東洋ろ紙製，100〜200 mesh)，そ れに，天然の食物繊維ではないが比較のために，発泡ス チロール粉末（発泡度 60 の発泡スチロール塊を $1 \mathrm{~mm}$ の円孔ふるいを備克た Wiley mill に通して粉碎したも の）も用いた。

GDF は，その SV 值を変えるために，粉研して粒度 の異なる 4 種の試料を調製し，打のおの番号を付けて区 別した。 まず GDF-1 は，発泡スチロール同様， $1 \mathrm{~mm}$ の円孔ふるいを借克た Wiley mill に通した乾燥粉末で あり，GDF-2 は，GDF-1 を 100 ィッシュ(Tyler, 目 開き $149 \mu$ のらるいにかけ，通過した分函である。 GDF-3 は，GDF-1 と同様にして調製したもので，粒度 も GDF-1 と同しで市るが，別のゴボウ原料から得られ たものである.

GDF-4，GDF-5 は，いずれる GDF-3 を出発物質とし て調製した。まず GDF-4 は，GDF-3 の一部を取ってメ

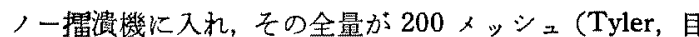
開き $74 \mu$ ）のるい学通るまで繰り返し粉碎したもので ある. 次に GDF-5 は，GDF-3 の一部を取って超低温粉 砕装直 (リンレックスミル LX-0 型, ホソカワミクロン
KK) で粉确した微粉末である．画像分析装置（Texture Analyse System，Leits 社製）による測定から，GDF-5

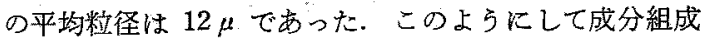
は等しくて精度だけが異なる 3 種試料（GDF-3，-4，-5） を調製した。

また GDF-3 を，希酶酸溶液下で亜塩素酸処理して， これの脱リグニン分画に相当するホロセルロース ${ }^{(4)}$ も 調製した。このように，出発物質 GDF-3 の粒度分布は 変えずに成分組成变变光た試料子用いた，各試料の固有 SV 值と, 飼料中の相対 SV 值は Table I K示した。

2. 食物織維の水中沈定体皘 (Settling volume : SV) の測定 SV 值は， $1 \mathrm{~g}$ の乾燤試料が抱水して平衡に 達したときの沈定体積（mI）を示すものであり，すでに 述べた方法 ${ }^{(3,6)}$ 亿準して測定した。な技 SV 值は，自然 状態での最大抱水量とよく平行し，両者が表軍一体の関 係炕ることるすで観察している(5)。発泡スチロール 粉末は撥水性であり，水に沈まないためその恋まの状態 で体積を測定した。

3. 相対水中沈定体皘 (Relative settling volume, RVS）の算出な扮飼料中の相対 SV 值は，各食物緎 維に固有の SV 值と，飼料中添加レベルを掛け合わせた 值で，これは飼料 $100 \mathrm{~g}$ 中の食物織維が抱水したときの 容積飞相当する。

4. 飼料と実験動物の扱い実験動物には，離乳直 後のウイスター系雄ラット（德島実験動物研究所）を用 い，4ない 5 日間，精製標準飼料（25\% カゼインーシ ヨ糖飼料 $)^{(6,7)}$ で予備飼育した後，試験を行った， 1 群 5 ないし6匹として個別ヶージで 3 週間飼育した。予備飼 育に用いた $25 \%$ カゼイン・ショ糖飼料を基本飼料とし， この基本飼料にアマランス（三栄化学工業社製）を 4 あ るいは $5 \%$ 源加したものを対照飼料とし，対照飼料にさ らに各被験試料を添加したものを試験飼料とした，アマ ランス，㸝よび各被験試料の添加は，ショ糖と置き換え て行った．飼料は，毎朝新鮮なものに取りかえて水とと もに自由に与えた。この間の飼料掑取量と体重は毎日記 録した。得られたデータは，Duncan ${ }^{(8)} の$ Multiple Range Test により有意差検定を行った.

\section{結果}

Table I は食物繊維の SV 値と，3回の実験で得られ た体重增加量ならびに成長回復率をまとめたものであ ろ. 実験ごとに，相対 SV 値の小さい順に示した。また 
Table 1. Effect of Particle Size and Settling Volume in Water of Dietary Fiber on Growth Restoration of Rats Fed a Purified Diet Containing 4 or 5\% Amaranth (Food Red No. 2)

\begin{tabular}{|c|c|c|c|c|c|}
\hline & $\begin{array}{c}\text { Particle } \\
\text { size } \\
\text { of DF }\end{array}$ & $\begin{array}{c}\text { Specific } \\
\text { SV of } \\
\text { DFi }\end{array}$ & $\begin{array}{l}\text { Relative } \\
\text { SV of DF } \\
\text { in diet }{ }^{2}\end{array}$ & $\begin{array}{l}\text { Body } \\
\text { weight } \\
\text { gain }\end{array}$ & $\begin{array}{l}\text { Percent } \\
\text { restoration } \\
\text { of growth }\end{array}$ \\
\hline$[\text { Experiment } 1]^{4}$ & $\mu$ & $\begin{array}{c}\mathrm{ml} / \mathrm{g} \\
\text { sample }\end{array}$ & $\underset{\text { diet }}{\mathrm{ml} / 100 \mathrm{~g}}$ & $\mathrm{~g} / 21$ days & $\%$ \\
\hline Basal diet & & - & - & $161 \pm 3.6^{\mathrm{a} .5}$ & 100 \\
\hline Basal diet $+4 \%$ amaranth (control) ${ }^{6}$ & & - & - & $58 \pm 17(3)^{\mathrm{b}, 7}$ & 0 \\
\hline Control $+5 \%$ GDF $-2^{8}$ & $<149$ & 13.5 & 67.5 & $140 \pm 7.2^{\mathrm{c}}$ & $79.6 \pm 7.0^{\mathrm{a}}$ \\
\hline Control $+5 \%$ GDF $-1^{9}$ & $<1,000$ & 23. 0 & 115 & $161 \pm 1.3^{2}$ & $99.6 \pm 1.3^{b}$ \\
\hline \multicolumn{6}{|l|}{$[\text { Experiment } 2]^{10}$} \\
\hline Basal diet & & - & - & $160 \pm 2.7^{\mathrm{a}}$ & 100 \\
\hline $\begin{array}{l}\text { Basal }+5 \% \text { Powdered } \\
\text { polystyrene foam }{ }^{11}\end{array}$ & $<1,000$ & 9.5 & 47.5 & $152 \pm 3.9^{\mathrm{a}}$ & - \\
\hline Basal $+5 \%$ amaranth (control) & & - & - & $95 \pm 9.2(5)^{b}$ & 0 \\
\hline Control $+5 \%$ cellulose $\mathrm{e}^{12}$ & $74 \sim 149$ & 5.0 & 25.0 & $84,132(2)$ & $-22,57(2)$ \\
\hline $\begin{array}{l}\text { Control }+5 \% \text { Powdered } \\
\text { polystyrene foam }\end{array}$ & $<1,000$ & 9.5 & 47.5 & $125 \pm 1.7^{\mathrm{c}}$ & $45.5 \pm 2.8^{a}$ \\
\hline Control $+5 \%$ GDF $-4^{13}$ & $<74$ & 10.0 & 50.0 & $134 \pm 4.4^{\mathrm{ed}}$ & $60.0 \pm 6.7^{\mathrm{a}}$ \\
\hline Control $+5 \%$ GDF $-3^{14}$ & $<1,000$ & 18.5 & 92.5 & $149 \pm 5.0^{\mathrm{ad}}$ & $84.7 \pm 6.9^{b}$ \\
\hline \multicolumn{6}{|l|}{$[\text { Experiment } 3]^{15}$} \\
\hline Basal diet & & - & - & $160 \pm 6.8^{\mathrm{a}}$ & 100 \\
\hline Basal $+4 \%$ amaranth (control) & & - & 一 & $91 \pm 2.2(5)^{b}$ & 0 \\
\hline Control $+3.5 \%$ GDF -516 & 12 & 7.0 & 24.5 & $133 \pm 7.7^{\mathrm{cd}}$ & $60.6 \pm 11.2^{\mathrm{ac}}$ \\
\hline Control $+5 \%$ Cellulose 12 & $74 \sim 149$ & 5.0 & 25.0 & $104 \pm 6.3^{b}$ & $18.1 \pm 9.1^{b}$ \\
\hline Control $+3.5 \%$ GDF $-3^{14}$ & $<1,000$ & 18.5 & 64.8 & $152 \pm 4.8^{80}$ & $88.2 \pm 7.0^{2}$ \\
\hline$+1.5 \%$ holocellulose ${ }^{17}$ & $<1,000$ & 44.0 & 66.0 & $125 \pm 5.9^{\mathrm{d}}$ & $49.8 \pm 8.6^{\mathrm{c}}$ \\
\hline
\end{tabular}

$1 \mathrm{SV}$ : settling volume $(\mathrm{ml} / \mathrm{g})$ occupied by $1 \mathrm{~g}$ of air-dried dietary fiber placed in water filled in a graduated cylinder. The volume was read off by naked eyes after 24 hr-equilibration to water. The volume of powdered polystyrene foam was determined as such in a cylinder not containing water.

2 Relative SV (RSV) of dietary fiber incorporated into diet was calculated as follows: [specific SV $(\mathrm{ml} / \mathrm{g})$ of each dietary fiber] $\times[$ its dietary level $\%)]$. RVS corresponds to the SV value of dietary fiber contained in $100 \mathrm{~g}$ of diet.

3 Percent restoration of growth $(\%)$ is expressed as follows : (difference in body weight gains between rats fed the test and control diets) $\times 100 /$ (difference in body weight gains between rats fed basal and control diets).

4 Average initial body weight was $71 \mathrm{~g}$ (range; 60 to $77 \mathrm{~g}$ ), each group consisted of 5 animals.

5 Mean $\pm S E M$; values not sharing a common superscript letter within a column in each experiment are significantly different $(\mathrm{p}<0.05)$.

- Food Red No.2, trisodium salt of 1-(4-sulfo-1-naphthylazo)-2-naphthol-3,6-disulfonic acid, purchased from San-ei Chemical Industries, Osaka.

7 The values in parentheses indicate the number of animals which survived and on which data are based when this number was less than the original number per group.

8 GDF-2 was a fraction of GDF-1 having particle size smaller than $149 \mu$.

- GDF 1 was prepared from the roots of edible burdock (Arctium lappa L.), powdered in a Wiley mill equipped with a $1 \mathrm{~mm}$ diameter pore sieve.

10 Average initial body wight was $64 \mathrm{~g}$ (range; 57 to $72 \mathrm{~g}$ ), each group consisted of 5 animals except for the control and control $+5 \%$ cellulose diet groups which consisted of 6 animals each.

11 A lump of polystyrene foam was powdered with a Wiley mill equipped with a $1 \mathrm{~mm}$ diameter pore sieve. Resultant powder was used for comparison although not dietary fiber by definition.

12 A preparation from cotton fiber (purchased from Toyo Roshi Co., Tokyo).

13 A part of GDF-3 was ground in an agate mortar until entire sample passed through a wire-mesh sieve with openings of $74 \mu$. 
14 GDF.3 was prepared by the same manner as that for the preparation of GDF-1, but harvested season and district were different. Therefore GDF 3 and GDF-1 had different SV.

15 Average initial body weight was $67 \mathrm{~g}(61$ to $75 \mathrm{~g})$, each group consisted of 6 animals, except for the group received the control diet which contained 7 aminals.

16 To obtain GDF-5, GDF-3 was ground as small as possible in frozen state with liquid nitrogen. The resultant material had mean particle size of $12 \mu$ as determined by Texture Analyze System (Leits, West Germany). We asked Drs. K. Yamada and K. Itoh of Nippon Reizo Co., Tokyo, for this preparation.

17 Prepared from GDF by delignification with sodium chlorite in diluted acetic acid medium ${ }^{(4)}$.

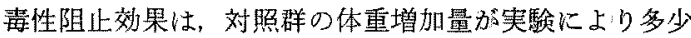
変動するので, 成長回復率 (Table I の脚注参照) でも 表した、すなおち，对照飼料群の体重增加量を基準（0 $\%$ に にして，試験飼料群の体重増加量が基本飼料群の それにはで完全回復した場合を $100 \%$ として表してい る.

実驗 $11 \mathrm{~mm}$ の円孔らるいを通過した全量（GD F-1）と，これから $149 \mu$ 以下の粒径のものをらるい分 けたGDF-2 の雨者で垡性阻止効果を比較した．SV 值 で GDF-1 より 40\% ほど小さいGDF-2 の成長回復率 は，GDF-1 のそれよりも約 $20 \%$ ではるが有意 $(p<$ 0.05)に減少した（Table I, Experiment 1).

実験 2 食物緎維のSV 值が，アマランス毒性阻止 効果の指標になるならば，化学組成が全く翼なり，微生 物学的にも汪とんど不活性な蹯水性の発泡スチロールで b，GDF に爪敵する SVさ充西れば十分効果を発揮す るはずである，また逆に，GDF の䊀径をさらに小さく して SV 值を下け゚ていった場合，いず机生理効果が消失 する臨界值があると推定される。ここではこれらの点を 检討した。

GDF-4 は，出発物留である GDF-3 の粒径をその半分

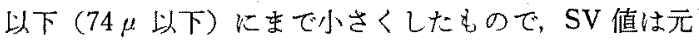
の $18.5 \mathrm{ml} / \mathrm{g}$ 加 $10 \mathrm{ml} / \mathrm{g}$ に低下 (約 $45 \%$ の減少) し ていた (Table I, Experiment 2). これの成長回復效果

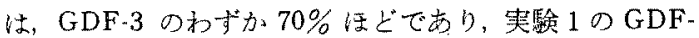
$2(20 \%$ 減）より一層の低下を示したが，生理効果が無 くなる程ではなかった，次に，発泡スチロールによる回 復効果は，これと SV 值のほぼ等しいGDF-4 と統計的 に差がなく，等洒であった。なお，発泡スチロール粉末 老基本飼料一単独添加した群の成長は，基本飼料群のそ れとはとんど変和らず，これ自体の成長への影響は何ら 認められなかった。

一方， SV 值が最小 $(5.0 \mathrm{ml} / \mathrm{g})$ のセルロース粉末で は，成長回復効果がみられなかったばかりか，二週目に

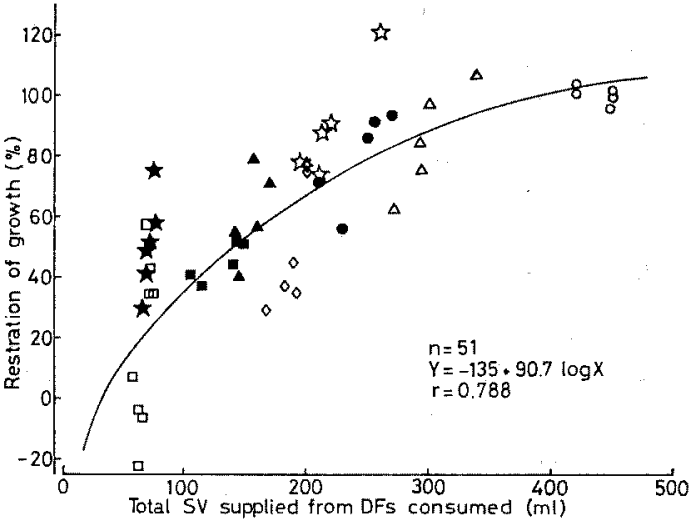

Fig. 1. Correlation between the Total SV Supplied from Dietary Fibers Consumed and Grow. th-Restoration of Rats fed a Purified Diet Containing 4 or $5 \%$ Amaranth (Food Red No.2). A logarithmic curve with following equation was given when percent restoration of growth (see footnote 3 of table I) was plotted against total VS supplied from dietary fiber consumed ssettling volume of each dietary fiber $(\mathrm{mg} / \mathrm{g})\} \times\{$ its intake for 21 days $(g)\} ; Y=-105+97.2 \log$ $X(r=0.828)$. Each point represents the value obtained from individual rat of groups given the following test diets: $0,5 \%$ GDF-1; $\bullet, 5 \%$ GDF-2 ; $\triangle, 5 \%$ GDF-3; $\triangle, 5 \%$ GDF $-4 ;$; $3.5 \%$ GDF $-3 ; \star, 3.5 \%$ GDF-5; $\square, 5 \%$ Cellulose ;, $5 \%$ Polystyrene foam $; \diamond, 1.5 \%$ Holocellulose. The rogarithsmic curve suggests that total $\mathrm{SV}$ of dietary fiber in diet consumed is a factor determining its protective activity and there is a requirement of $\mathrm{SV}$ to attain the protective effect.

入って 5 匹中 3 匹が死亡した。

実験 3 : GDF-3を，液体壆素凍結下で粉砕を行 5 超低温粉䂗装置に通す上，平均粒径 (GDF-5) が得 られ，そのSV 值は $7.0 \mathrm{ml} / \mathrm{g}$ にすで低下 した (Table I)，粒径の最む小さいこのGDF-5 は；実験 
で全く効果が見られなかがた $5 \%$ ヒルロース飼料の相 対 SV 值 $(25 \mathrm{ml} / 100 \mathrm{~g}$ diet $)$ と等しくなるように, これ を3.5\% 添加（相対 SV; $24.5 \mathrm{ml} / 100 \mathrm{~g}$ diet）して両者 の生理効果を比較した: 結果は，GDF-5 の成長回復率は GDF-3 のそれより有意に低下したものの, ヒルロース のそれよりは明らかに高く，この場合です GDF は依然 有效であることを示していた(Table I, Experiment 3).

一方，GDF-3 の脱りグニン分画であるホロセルロー スは, 測定の結果, 元の二倍強の SV 值 $(44 \mathrm{ml} / \mathrm{g})$ を有 していた、したがって、ホロセルロースは，GDF-3 の半 分の添加レベルで両者の相対 SV 值はほほ等しくなる。 しかし生理効果を調べた結果では，ホロセルロースはわ ざか $1.5 \%$ で有效性を発揮したものの，GDF-3 と等価 の成長回復率を示すまでには至らなかった。

Fig. 1 は，食物繊維を含を被騟試料から供給された SV 総量亡, 成長回復率の関係を，実験 $1 \sim 3$ 学通して 各個体ごとに $(\mathrm{n}=51)$ プロットしたものである。供給 された SV 総量は，被験飼料の相対 SV と 3 㥜間の飼料 摄取から計算により求めることができる、因の曲線は, 对数回㷌式 $(\mathrm{Y}=-135+90.7 \log \mathrm{X})$ 加得られたもの で，各種の食物繊維から供給された SV 総量と，成長回 復效果の間には明らかな相関 $(r=0.788)$ が見られた。 この図から，食物繊維は，その成分，粒度，飼料中添加 レベルが異なっていても，一定レベルのSVさえ供給で きれば有効性を発揮しらることを示唆していた。

\section{考察}

すでに Kirwan ら帛は，粒度の異なる小麦つスマで 排便頻度や一回の排便量をヒトで調べ，粒度が大きくな ると保水量が増し，排便頻度や，排便量が増加すること を観祭している.これらの結果は，食物緎維の精度雤化 に伴ら物性の变化が，各種の生理作用にも影響すること を示惨すもので方り，食品の調理，加工の際に考慮す心゙ き点と思われる．本奏験では，粒径の異なる食物繊維を 調製し，水中沈定体積とその生理効果への影響を調べ た.

実験1で見られたよらにアマランスを 4\% 添加する と，とくに初期の 14 日間ぐらいは著しい成長荤延が生 じ，死亡するラット在現れる。このときの死亡率や，生 存ラットの成長暒延の程度は, 奏験 2 の $5 \%$ 投与時より 毛著しかったラットの供給者（德島実験動物研究所，
德鼻)，系統 (Wistar)，飼料組成 (25\%力ゼインーショ糖 飼料)；攵の他の飼育条件は同じでむ実験ごとにこうし た变動は，しばしば観察される(3,6,7)。ロットごと異な るアマランス夾䧴物の影䀺とも考えられる。

次に，食物䋐維試料学粹度の違いでふるい分けた場合 に，構成成分のかたよりを生ずる可能性があり，実㐨 1 の GDF-1 と GDF-2 の生理效果の差は, そのような相

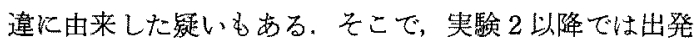
物質の一部を取り，そのすべてが目的のふるいる通るむ で粉䂶して構成成分のかたよりをなくした，それでも粒 度を小さくして SV 值を下げると，生理効果は明らかに 弱くなることが再現された（Table I). また発泡スキロ 一ル数末でる，十分有效であることがわかった（Table I, Experiment 2).

各種食物繊維の成長回復効果と，それらの摂取により 供給された SV 総量との関係は, 直線回帰式よりる詨数 回㷌式に従っていた（Fig. 1)。これは，生理効果にはプ ラトーに達するレベルがあることを考劣れば当然かる れない，したがって，成長回復效果が平衡に達するとき の飼料中 SV 量は，每性阻上效果のための SV 必要量と みることもできる、また，末知飳料でもその SV と，試 料中の添加レベルがわかれば生理効果の強さをある程度 予測できる可能性がある.

最も, 相対 SV 值が等しくても一致した生理效果が得 られなかった試料るいくつか見られた。たと亲ば $3.5 \%$ GDF-5 と5\%七ル口ース粉末は，ほぼ等しい相対 SV 值を有するにもかかわらず，生理効果は等洒ではなく (Table I，Experiment 3)，前者の効果が大きかった。同 様に，3.5\% GDF-3 と $1.5 \%$ ホロセルロースも，相対 SV 值を等しくしたにもかか放らず，生理効果は前者の 注らが大きかった。こうした相違は，有塚ら ${ }^{(10)}$ の食物緎

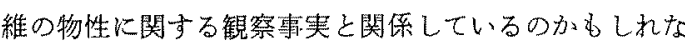
W.

有塚らは，食物瀻維試料にプロテアーゼやリバーゼを 作用させると SV 值が大輻に增加することを見出した。 したがって，本研究で用いた GDFは变たタンパタ質 や脂質を含んだ粗製の試料なので，これらが消化管腔内 を移動する際には，消化䤃素の作用をらけて物性が変化 する可能性がある。つまり，相対 SV 値の等しい試料間 で等洒の效果が得られなかったのは，消化管腔内（in vivo）では両試料間の SV が必ずしも一致していなから たためかもしれない、実際，各食物紻維を酵素処理する 
と SV 值肪增し, この in vitro SV 值の増加に伴って, 処理前のそれよりも生理効果（アマランス毒性阻止効 果）が高くなるという結果を得ている(10).

\section{要旨}

食物繊維は，アマランス（食用赤色 2 号）の4ないし 5\% 添加によるラットの成長拥制を注济完全に阻止する が，ここでは食物緎維の水中沈定体積 (Settling volume in water, $\mathrm{ml} / \mathrm{g}$ dry sample, 以下 SV) と, 噖性阻止効 果に及ぼす粒度の影響を調べた。また，相対 SV（食物 緎維固有のSV 值×食物繊維の添加レベル）の等しい 飼料間で生理効果の等価性について子検討した，被験試 料には、ゴボウから調製した粒径の異なる4 種試料 (GDF) の他, 発泡スチロール粷末 $(\mathrm{SV}=9.5)$, 市肘セ ルロース粉末 $(\mathrm{SV}=5.0)$ \&比較に用いた. GDFは, 粒 度の低下に伴って SV 值が小さくなりこれにつれて成 長回復効果も弱くなった。.しかし，添加レベルを調節し て GDF の相対 SV 值を，無効であったセルロース粉末 のそれと等しくした場合でも，GDF の効果は消失しな かった。をた木胡ルロースは高いSV 值を有してい たが，相対 SV 值をGDF のそれとそろえた場合に，後 者ほどの効果は見られなかった，今回，発泡スチロール 粉末でも有効であることもわかった，以上の結果から非 水溶性食物織維については，消化管腔内を “一定容積” を保らながら移動することが，この種の効果の発現に重 要な意義があるものと思われた，また，管腔内での容積 形成には，in vitroでは現れない食物絨維の質的な差も 影響していることが示唆された。

超低温粉砕装惪（リンレックスミル LX·0 型, ホソカ ワミクロン KK) に上るゴホウ食物瀻維の微粉末飼料 (GDF-5) は，株式会社ニチレイ研究所の伊東 克所長， 山田耕二前所長の御好意に上り調製して頂いた。ここに 厚くお礼申し上げまず。
(1) B. H. Ershoff and E. W. Thurston: J. Nutr. 104, 937 (1974)

（2）永井鞆江，今村裕一，海老原清，桐山修八：栄 盖と食糧，31，161 (1978).

(3) H. Takeda nad S. Kiriyama: J. Nutr., 109, 388 (1979).

（4）芝本武夫（代表）：「林産化学実験書（第 3 版）」 産業図書, 1965，p.103.

（5）武田秀敏，桐山修八分担：「食物䋐維の物理化 学的性質」, 食物繀維，印南 敏 - 桐山修八編, 第一出版，1982，p. 57 .

（6）武田秀敏，海老原清，林 芳文，桐山修八：農 化，53，291 (1979).

（7）武田秀敏，海老原清，桐山修八：農化， 55, 125 (1981).

（8）柴田窅三：「生物統計学序説」，㓱文社，1974， p. 64 .

(9) W. O. Kirwan, A. N. Smith, A. A. McConnell, W. D. Mitchell and M. A. Eastwood: Br. Med. J., 4, 187 (1974).

（10）有塚 勉，武田秀敏，桐山修八：第 44 回日本 采羡・食糧学会総会講演要旨集， 1990，p.52.

(11) B. H. Ershoff and E.W. Thurston: "Effect of diet on amaranth (FD \& C Red No.2) toxicity in the rat," $J$. Nutr., 104, 937 (1974).

（12）永井鞆江，今村裕一, 海老原清, 桐山修八：「各 種野菜残渣拉よびュンニャクマンナンによる食 用赤色 2 号の毒性阻止効果ならびに塩混合組成 の影瞳」，栄養之食糧，31，161（1978）.

(13) H. Takeda and S. Kiriyama : Correlation between the physical properties of dietary fibers and their protective activity against amaranth toxicity in rats," $J$. Nutr., 109, 388 (1979).

（14）武田秀敏, 海老原清，林 芳文，桐山修八:「食 用赤色 2 号むるいはマミ，酸過剩害性に対する 各種食物センイ (dietary fibers) の影響」, 求 化, 53, 291 (1979).

（15）川端俊治：「新訂 加工食品と食品衛生」新思潮 社, 1984.

（16）桐山修八：「食慨性有害物賀の毒性阻止作用」, 食物繊維, 印南 敏・桐山修八編，第一出版， 1982, p. 193. 